\title{
A RELAÇÃO CIDADE-RAÇA-CAPITAL NO ESPAÇO URBANO CARIOCA: UMA ANÁLISE DAS REMOÇÕES NO PERÍODO PREPARATÓRIO PARA OS MEGAEVENTOS ESPORTIVOS
}

\author{
THE CITY-CAPITAL RACE RELATION IN CARIOCA URBAN SPACE: AN ANALYSIS OF REMOVALS IN THE RUN-UP TO \\ SPORTS MEGA-EVENTS
}

\section{RESUMO}

O trabalho a que se propõe este artigo é analisar a remoção e a resistência no espaço urbano carioca com o esforço constante de observar a relação cidade-raçacapital. A análise se embasou em uma revisão de literatura sobre estudos e pesquisas sobre as remoções em período recente da história carioca: os preparatórios para os megaeventos esportivos. Primeiramente aborda-se o capitalismo contemporâneo, sua relação com o espaço e correlações da atual crise financeira com o espaço urbano carioca. Em segundo, recorta-se o objeto de análise trazendo o foco para os processos de remoção e resistência nos preparatórios dos megaeventos de 2014 e 2016, período posterior à crise econômica de 2007/2008 e momento em que os efeitos dessa crise eram intensos em todo o mundo. Após esta etapa, apresentam-se alguns estudos sobre algumas comunidades removidas procurando sempre centralizar a variável raça. Por fim, expõe-se uma das formas de resistência engendradas pela população atingida. Foi observado que a população se organizou em comitês populares, fóruns e associações em conjunto com pesquisadores e acadêmicos universitários; além da mobilização e uso político do Direito e de instituições estatais para combater a própria ação estatal de remoção. Conclui-se que limitar o estudo do espaço urbano à relação cidade-capital olvida a dupla opressão (de classe e raça) que pessoas não brancas podem sofrer na cidade. Além disso, conclui-se pela exigência por cidadania (o direito a ter direitos) pela população quando dos processos de resistência e uma certa esperança normativa no Direito durante este processo.

Palavras-chave: megaeventos; capitalismo; raça; Rio de Janeiro; remoção.

\begin{abstract}
The purpose of this paper is to analyze the removal and resistance in the urban space of Rio de Janeiro with the constant effort to observe the city-race-capital relationship. The analysis was based on a literature review on studies and research on removals in recent period of Rio's history: the preparations for the mega-events. Firstly, contemporary capitalism, its relationship with space and the correlations of the current financial crisis with the urban space of Rio are addressed. Second, the focus was brought to the processes of removal and resistance in the preparations for the mega-events of 2014 and 2016, after the economic crisis of 2007/2008 and when the effects of this crisis were intense throughout the world. After this step, some studies on some removed communities are presented, always trying to centralize the race variable. Finally, one of the forms of resistance engendered by the affected population is exposed. It was observed that the population was organized in popular committees, forums and associations together with researchers and university academics; in addition to the mobilization and political use of Law and state institutions to counter state removal action itself. We conclude that limiting the study of urban space to the city-capital relationship oblivious to the double oppression (of class and race) that non-white people may suffer in the city. In addition, it concludes by the requirement for citizenship (the right to have rights) by the population during the processes of resistance and a certain normative hope in Law during this process.
\end{abstract}

Keywords: mega-events; capitalism; race; Rio de Janeiro; removal.
Natália Sales de Oliveira ${ }^{a}$

${ }^{a}$ Universidade do Estado do Rio de Janeiro (UERJ), Rio de Janeiro, RJ, Brasi

DOI: $10.12957 /$ geouerj.2020.48408

Correpondência:

nataliasoliveira32@gmail.com

Recebido em: 27 set. 2019

Revisado em: 19 out. 2019

Aceito em: 16 dez.2019 


\section{INTRODUÇÃO}

Estudar academicamente a cidade e a construção de seu espaço habitado é simultaneamente um estímulo e um desafio. Um estímulo por ser o local em que se vive, onde se materializam as relações sociais. A cidade circunda o pesquisador, estimulando observações cotidianas. Entretanto é também um desafio por facilitar erros empiristas ao se fazer análises que considerem apenas o lugar, não considerando a história das relações sociais e o que as produziu (SANTOS, 2014). Há o fácil erro de não se preocupar com a totalidade social que produz a cidade, em não observar as dinâmicas subterrâneas que envolvem a aparência, superficilidade do lugar. É com esse esforço de compreensão da totalidade que se analisa o espaço urbano carioca.

Quando se propõe a estudar o espaço urbano, nota-se que a essência da teoria crítica sobre o assunto é elaborada com base em categorias marxianas. Elas apontam que o espaço urbano não é algo dado pela natureza, mas produzido pelo homem. A construção e reconstrução desse espaço são elementos importantes na manutenção da ordem capitalista, pois ele seria, simultaneamente, produto e produtor da sociedade, no sentido de intervir nos fluxos de circulação, na organização do trabalho produtivo, nas redes de distribuição, etc. A compreensão do espaço urbano como produção capitalista é fundante, portanto, para esta pesquisa. Autores como Henri Lefebvre (2008), um dos primeiros a compreender a relação íntima entre reprodução social e espacialidade, David Harvey (2005) e Neil Smith (1979) são referenciais importantes neste quesito. Estes autores perfazem a gama de pesquisadores que produzem o que denomino de "teorias hegemônicas", aquelas análises estrangeiras produzidas por autores de localidades centrais, como Europa e Estados Unidos, e que correlacionam a produção do espaço com o desenvolvimento capitalista e, por vezes, com a atuação estatal. Esses autores apontam a relação intrínseca entre a cidade e o capital e, ao final, a capacidade que agentes capitalistas têm em formatar e reinventar o espaço urbano.

Autores brasileiros dedicados ao tema se inspiram nessa literatura para analisar o espaço em que vivem. É o caso de Ribeiro (1997), que analisa as formas de produção de moradia na cidade do Rio de Janeiro, apontando a transformação da lógica de habitação e da participação dos setores imobiliários nesse aspecto. O autor chega a indicar a emergência da produção capitalista da moradia, possível em razão do surgimento e autonomização de um capital de circulação que permitiu o investimento da produção de moradia. Abreu (2006), por sua vez, analisa a estrutura urbana do Rio de Janeiro desde o início do século XIX e constata vários responsáveis pela evolução urbana, porém foca a atenção no papel desempenhado pelo Estado. Conforme o autor, o modelo segregador do espaço urbano carioca se deu em função dos interesses do capital com legitimação indireta do Estado. O modelo de ocupação do espaço carioca seria, portanto, com núcleo hipertrofiado, concentrador de renda e de recursos urbanísticos, com estratos urbanos periféricos ao redor, os quais são carentes de serviços e infraestrutura à medida que se afastam do centro. São esses últimos locais 
que servem de moradia para a população de baixa renda. $\mathrm{O}$ autor afirma que a estrutura metropolitana se compõe em núcleo, periferia imediata e periferia intermediária. Aqui já se expõe a expulsão de pobres de determinadas áreas da cidade. Uma das formas para tanto estava, até mesmo, na ação direta do Governo, quando este praticava, por exemplo, a renovação urbana numa área central desvalorizada, não reassentando as pessoas ali residentes. $O$ autor, então, formula a tese de que a estratificação social no Rio de Janeiro foi decorrente de ação pública estatal.

Encaminhando-se no mesmo sentido, Botelho (2007) analisa o histórico brasileiro de políticas públicas de moradia e evidencia que o grande mote dos principais programas habitacionais se deu com a criação do financiamento de moradia. A aliança com o setor privado para construção de moradias foi marcante, acarretando na declarada marginalização do setor mais vulnerável, de baixíssimos rendimentos.

A literatura sobre o assunto apresenta alguns planos e políticas públicas empregadas ao longo da história local. São políticas e legislações por vezes identificadas nessa literatura como sanitaristas e/ou higienistas que pautavam pela remoção de indesejados (historicamente, ex-escravos, pobres e negros). Elas indicam uma ação do poder público em criar ou reforçar a produção de um espaço urbano segregado e, por vezes, excludente, através de obras e planos de planejamento urbano. É o que se constata em obras de Maurício de Abreu, Oswaldo Porto Rocha e Lia de Aquino Carvalho, todas constadas na bibliografia abaixo, em que se apresentam a reforma urbana de Pereira Passos e demais obras de planejamento urbano ao longo da história carioca, que buscou reconstruir e produzir espaços urbanos capazes de viabilizar a atração de capital e investimentos locais.

Os autores tendem a mostrar que a produção do espaço se relaciona com os processos de acumulação capitalista, e a segregação espacial se correlaciona com a atuação do mercado imobiliário, atuação estatal no planejamento urbano com fins de atrair investimentos. Tem-se, portanto, uma literatura que evidencia a segregação espacial e a analisa sob a lente da renda.

Diferentemente, há outra vertente literária que se embasa naquela acima mencionada, mas acrescenta a análise de outra variável pouco considerada como elemento essencial da segregação espacial: a segregação racial. Neste último quesito, trazem-se como literatura importante aquelas obras que tratam da ocupação do espaço após a abolição. Esta vertente aponta a escravidão, a Lei de Terras e abolição da escravatura como elementos cruciais para se compreender a atual segregação espacial. Andrelino Campos (2010) apresenta a tese de que as favelas cariocas são uma espécie de transmutação de quilombos periurbanos. Nesta obra, o autor demonstra fatos que permitem identificar como origem das favelas tais quilombos, os quais existiam antes e depois da abolição da escravatura, mostrando haver subsídios para se refletir sobre uma produção diferenciada do espaço urbano, no caso racializada, em razão do histórico do colonialismo e da escravidão. 
Carril (2006), embora analisando o espaço urbano de São Paulo, apresenta que a formação territorial capitalista brasileira é fundamental para compreender a segregação espacial e racial. A condição do negro imposta pela escravidão, segundo a autora, se mantém como parte contínua das bases de produção e de reprodução do capital na agricultura e no espaço urbano. Dessa forma, os processos de metropolização em São Paulo recriam hierarquização por cor: a força de trabalho do trabalhador negro, estabelecida como de menor valor, implicaria em baixos salários, empurrando-o para os cortiços e favelas. A autora aponta como momento fundador dessas relações o processo da utilização da força de trabalho escrava que construiu a riqueza agrário-urbana e na elaboração de uma legislação de acesso à terra. A segregação, portanto, teve fundamento na propriedade privada da terra desde 1850 (Lei de Terras) separando aqueles que podem acessar a propriedade da terra (que a partir da Lei de Terras é identificada com mercadoria) e os não proprietários. A abolição, por não inserir o ex-escravo como trabalhador livre e nem o reproduzir como trabalhador por tê-lo forçado a competir com o imigrante europeu, intensificou tal segregação. O negro fica, então, condicionado às formas de superexploração, e as opções de moradia foram os cortiços e favelas. Esses eventos históricos então, teriam repercutido ao longo dos anos futuros.

Ainda conforme a autora, a distribuição espacial no século XX na cidade de São Paulo caracterizou-se pelo padrão periférico de crescimento e com segregação conforme classes sociais. Nesse sentido, os códigos de condutas municipais definiam os locais ditos higiênicos e identificavam os moradores indesejáveis, incentivando um modelo de urbanização baseado no binômio legalidade/ilegalidade (atendimento ou não à legislação). Assim, nas habitações ditas higiênicas e legais encontravam-se classes sociais médias e altas; nos espaços em desconformidade com a legislação, encontravam-se negros e pobres.

A autora evidencia que o Estado, ao longo do século $X X$, por meio de políticas públicas promove urbanização e cria espaços ilegais na cidade, onde a classe trabalhadora se recriava sem infraestrutura e sem acompanhar a ordenação da lei. O Estado então, elabora legislações urbanísticas que favorece, através dela, a especulação imobiliária.

A pesquisa de Garcia (2006) aponta algo similar ao analisar os microdados do Censo do IBGE de 2000 e recorte territorial por Área de Expansão Demográfica (AED). Ela identifica a estratificação social na cidade do Rio de Janeiro, em que desigualdade racial e segregação urbana na cidade andam juntas. A autora demonstra em sua tese que a metrópole recria a hierarquia racial e que essa estratificação racial se relaciona intimamente com os locais de moradia. Identifica-se a correlação do espaço ocupado com quem o ocupa, demonstrando a estratificação racial nas localidades metropolitanas.

Observa-se que essa segunda vertente aponta para uma segregação espacial em razão de classe e raça. Sendo que, nesta última, haveria uma correlação intensa e direta entre a segregação espacial, escravidão e colonialismo. 
É importante evidenciar, portanto, que a literatura sobre espaço urbano brasileiro não pode focar sua análise somente na relação cidade-capital, pois os contextos históricos brasileiros fomentaram uma produção espacial diferenciada daquelas de países centrais. Há no Brasil, aliada à segregação espacial, a segregação racial. Ambas caminham juntas. Além do fato de que a própria constituição do modo de produção capitalista ter se dado de forma diferenciada também em virtude do colonialismo. Dessa forma, limitar a análise da configuração do espaço urbano carioca e suas transformações considerando apenas a lente da produção capitalista é insuficiente, pois apreende parte da complexa relação social. Como será melhor assinalado ao longo deste texto, o contexto brasileiro requer a consideração da variável raça nas análises. Assim, aproximase mais de um esforço de totalidade, como falado acima. Ainda assim, não se compreenderá todas as imbricações sociais retratadas no espaço urbano, mas caminha-se no sentido de ampliação do escopo de visão.

No espaço urbano carioca essa correlação entre estratificação social e racial evidenciadas no território é ainda mais perceptível. Como dito acima, foi possível constatar que o espaço urbano carioca fora um local onde existiram quilombos periurbanos (formações de resistência onde viviam escravos fugidos, ex-escravos, pessoas à margem da lei etc.); cortiços, onde historicamente viveram pessoas pobres e escravos libertos; e favelas, onde historicamente viveram pessoas pobres e negras que não podiam arcar com a vida na "cidade legal". As favelas continuam a existir e, embora possam não ter aquelas mesmas características tradicionais, nelas ainda há uma significativa parcela de pessoas negras em sua população (IPEA, 2011).

Dessa forma, compreender a configuração da territorialidade carioca não se restringe a entender como espaço e lógica capitalista se inter-relacionam. Há de se considerar a variável raça nesta análise.

Tendo em vista esse ponto de partida, o objeto de análise a que se dedica é a remoção e a resistência no espaço urbano carioca. A análise será desenvolvida com o esforço de observar a relação cidade-raça-capital. Dessa forma, em primeiro pretende-se compreender o capitalismo contemporâneo, sua relação com o espaço e correlações da atual crise financeira com o espaço urbano carioca. Em seguida, localizo o objeto de análise nos processos de remoção e resistência nos preparatórios dos megaeventos de 2014 e 2016, período posterior à crise econômica de 2007/2008 e momento em que os efeitos dessa crise estavam em pleno vapor em todo o mundo. Posteriormente, apresento alguns estudos sobre algumas comunidades removidas procurando sempre centralizar a discussão da raça. Por fim, apresento alguns estudos sobre tais processos que foram feitos à época apresentando uma característica interessante: uma das formas de resistência da população atingida. Observa-se que a população se organizou em comitês populares, fóruns e associações em conjunto com pesquisadores e acadêmicos universitários; além da mobilização e uso político do Direito e de instituições estatais para combater a própria ação estatal de remoção. 
O capitalismo contemporâneo e as cidades: a lógica do capital fictício para o espaço urbano

A proposta desta seção é compreender o que determina o capitalismo contemporâneo, como isso se relaciona com a atual crise econômica e, ainda, como tudo isso se correlaciona com o espaço urbano. Tratase de um caminho gradual importante que permitirá analisar alguns aspectos do espaço urbano carioca tendo em vista a teoria crítica da produção espacial.

A resposta construída para a crise estrutural econômica, administrativa e política dos anos de 1960 e 1970 originou o que conhecemos atualmente como capitalismo contemporâneo, que alguns autores apresentam como capital financeiro. Houve a mudança da lógica de acumulação e apropriação do capital para a lógica do capital fictício. Este é uma categoria apresentada por Marx no terceiro livro d'O capital (2017) e se define como um desdobramento dialético do capital portador de juros. Como no capitalismo tudo pode ser mercantilizado, o capital, enquanto capital, pode se tornar uma mercadoria que será comprada e vendida. Assim, o proprietário da mercadoria capital se apropria de parte do mais valor produzido na forma de juros. Constrói-se um montante de capital com base nesse rendimento, forma de apropriação de mais valor, que fora auferido de forma periódica, ao se aplicar taxa de juros de mercado. Assim, abre-se a possibilidade de se capitalizar ainda mais com a mera expectativa de ter apropriação futura. Logo, o capital fictício é a promessa de pagamento, é um rendimento que se espera manter no futuro. Se no capital portador de juros a lógica é aplicar a taxa de juros a um capital pré-existente (oriundo de mercadorias produzidas) e assim conseguir o rendimento; no capital fictício há uma inversão: vende-se para o comprador a possibilidade deste se apropriar de algo que ainda não existe, mas que espera-se que vá existir no futuro. "Entretanto, do ponto de vista da totalidade do capitalismo, constitui um capital fictício, na medida em que tem como base a mera expectativa de algo que pode nem se constituir" (CARCANHOLO, 2011, p.3).

Neste ambiente é que se estrutura a abertura e desregulamentações de mercados financeiros; expandese a criação de títulos de crédito que garantem a apropriação de algum valor ainda não produzido. Logo, a partir dos anos 70 quando havia uma massa de capital produzida em excesso e que precisa ser valorizado, tem-se então a expansão de um setor que se especializa tão somente na apropriação.

É neste contexto que se formou a grande crise econômica de 2007/2008. Carcanholo (2011) expõe que esta crise já havia sendo ensaiada há tempos, quando do estouro da bolha das empresas pontocom e também, como aponta Varoufakis (2016), por fraudes como da corporação Enron. Neste primeiro momento, os efeitos prejudiciais da crise foram, em certa medida, contidos. Até a crise de $2007 / 2008$, as medidas tomadas por Alan Greenspan, presidente do Sistema de Reserva Federal norte-americana (American Federal Reserve - FED) de 1987 até 2006, foram suficientes para amenizar os efeitos prejudiciais de crises. A receita era simples, nos momentos de crescimento econômico, a postura do FED era de não intervenção. Quando uma bolha 
estourava, o FED agia abaixando taxas de juros e/ou levando dinheiro para os mercados estabilizando a situação (VAROUFAKIS, 2016).

Como resposta à crise de 2001, o capital acumulado naqueles setores foi redirecionado para o mercado financeiro de imóveis. Como já estávamos em um contexto de desregulamentação financeira desde os anos 60 , as instituições financeiras tiveram seu controle drasticamente reduzido. "O crescimento do mercado imobiliário teve como sustentação exatamente o financiamento via empréstimos bancários com base em crédito hipotecário, ou seja, um financiamento que traz como garantia para o credor os próprios imóveis adquiridos" (CARCANHOLO, 2011).

Com a recessão causada pela crise econômica em 2001 nos Estados Unidos, o Banco Central Americano (Federal Reserve) apresentou como solução o corte de juros. Essa recessão ocorreu em função de um colapso nas despesas. Assim, a existência de gastos em consumo corrente ajudou a aliviar essa queda na economia. Além disso, na década de 90 a competição, as políticas públicas e os serviços financeiros fizeram com que fosse alterada a prática de hipotecas ao minimizar os padrões de segurança, reduzindo requerimentos de pagamento e expandindo mercados secundários, nos quais obrigações daqueles que fazem o empréstimo são trocadas como ações. Após as crises dos anos de 1970 e 1980, o mercado de hipotecas nos Estados Unidos mudou bastante, principalmente a partir da década de 90 em que as hipotecas eram realizadas sem que se avaliasse a condição de pagamento do tomador do empréstimo. Como se não bastasse, esses títulos foram demasiadamente alavancados pelas instituições financeiras. Foi essa prática a responsável pela disseminação de títulos tóxicos pelo mundo e que causou a severa crise financeira dos subprime em 2007/2008. (OLIVEIRA, 2017).

Para compreender a correlação entre capitalismo contemporâneo e espaço urbano será necessário lançar mão do conceito de renda da terra. A partir de então, observada a primeira correlação, será possível delinear as correlações inicialmente pretendidas.

Como mencionado acima, o espaço produzido pelo homem é importante dentro das relações sociais capitalistas. Essa análise foi inspirada na teoria da renda da terra, categoria já analisada por vários autores da economia clássica como Ricardo, mas que fora desenvolvida por Marx. Conforme este autor, a renda da terra é uma das formas específicas de apropriação do mais valor produzido.

A possibilidade de auferir a renda fundiária se fundamenta no monopólio que alguns têm sobre o solo, na propriedade privada que se constituiu. Sendo proprietário privado da terra, esta poderá se tornar sua mercadoria e, assim, seu monopólio poderá ser valorizado. Dessa forma, o proprietário fundiário pode arrendar sua terra para um capitalista (ou seja, o capitalista e o proprietário da terra não precisam ser a mesma pessoa) que pagará salários para os reais cultivadores da terra e em razão dessa permissão de uso de suas 
terras, receberá "uma soma em dinheiro fixada por contrato" (MARX, 2017, p.679). Essa soma é a renda fundiária, a forma pela qual a propriedade fundiária se valoriza. O fato de ser proprietário da terra dá o direito de apropriar-se da produção do valor na forma da renda da terra. Essa base de pensamento contribui para se compreender a renda fundiária para além das questões agrícolas e de mineração, embora Marx restringiu-se a elas no livro.

A partir da análise destas categorias, Harvey não se restringe à "terra" de forma literal, mas a espaço. Ampliando-se aí a possibilidade de utilizar tais categorias para auxiliar a compreender também o espaço urbano. Além disso, ele explica que a teoria da renda da terra de Marx expõe como a terra, que não tem valor por não ser fruto de trabalho humano, pode ter preço (por isso preço irracional) e ser trocada como mercadoria. Porém, a partir desta teoria se pode observar algo ainda mais elaborado: o direito a terra ser compreendido como uma forma de capital fictício.

A partir desta base, Harvey observa que o preço do espaço da produção capitalista abarca o direito de se apropriar da renda da terra, ou seja, “(...) o que é comprado e vendido não é a terra, mas o direito à renda fundiária produzido por ela" (HARVEY, 2013; p. 532). Ao fim, o comprador adquire o direito à renda futura que se espera seja mantida, adquire-se, portanto, o direito de se apropriar de algo que ainda não fora produzido. Ele explicita então a importância de se analisar o mercado fundiário onde a comercialização da terra terá grande incidência da especulação. A renda fundiária é o objeto da especulação.

Nota-se que o espaço é importante, pois é nele que se dará a produção de mercadorias, a sua distribuição e comercialização. Daí a centralidade da relação espaço urbano e capitalismo dada por teorias de produção do espaço urbano. Entretanto, essa relação não se exaure neste ponto.

No primeiro livro d'O capital, Marx se utiliza de uma expressão para explicar o processo de gênese do capitalismo na Inglaterra. Ele expõe que foi através da acumulação primitiva que se permitiu o processo de afirmação do modo de produção capitalista. Nesta acumulação, processo ainda não capitalista, a nascente burguesia dissocia os trabalhadores dos meios de produção ao expropria-los de terras comunais, local de produção de sua sobrevivência. As terras foram cercadas e as propriedades feudais se tornaram propriedades privadas modernas. Os trabalhadores que não as possuíam, como forma de sobrevivência, passaram a ter de vender sua força de trabalho para conseguir sobreviver. Conforme o autor, esse processo não teria ocorrido de forma idílica, mas por formas por vezes violentas através de legislações sanguinárias e conquistas imperialistas. (MARX,2013; LEITE, 2017). Dessa forma, impulsionou-se artificialmente a transformação do modo de produção feudal para o modo capitalista com o surgimento de arrendatários capitalistas, mercado interno, capitalismo industrial, etc. Essa acumulação primitiva teve diferentes momentos ao longo da história europeia, conforme Marx, "Na Inglaterra, no fim do século XVII, esses momentos foram combinados de modo 
sistêmico, dando origem ao sistema colonial, ao sistema da dívida pública, ao moderno sistema tributário e ao sistema protecionista" (MARX, 2017, p. 821).

A partir deste conceito, alguns autores passam a compreender que este processo não se daria tão somente em um período prévio ao capitalismo, mas mesmo quando este já está consolidado. Expropriações continuam a acontecer como forma de se permitir que haja ainda mais acumulação de capital.

É nesta vertente que caminha Rosa Luxemburgo ao expor que a acumulação capitalista necessita, para seu desenvolvimento, de um ambiente de formações sociais não capitalistas (um fora não capitalista) para conseguir absorver o excedente produzido pelo "dentro" capitalista. Dessa forma, o imperialismo seria a expressão política da acumulação do capital em seu esforço para conquistar locais não capitalistas para a absorção de excedentes produzidos no ambiente capitalista. É dessa forma que a autora justifica a necessidade imperialista de colonização por países europeus no século XIX. As colônias seriam o "fora capitalista", os ambientes ainda não imersos nesse modo de produção. Neles, os nativos seriam expropriados de suas terras para se tornarem trabalhadores livres para vender sua força de trabalho (isso quando não escravizados) e se tornarem aptos a consumir os excedentes produzidos na metrópole. Além de criar novas propriedades privadas para a produção e reprodução das relações capitalistas. (LUXEMBURGO, 1970; LEITE, 2017)

Harvey, inspirado na teoria do imperialismo de Rosa Luxemburgo, expõe a tendência do estado de superacumulação capitalista. Conforme o autor, os capitalistas sobrevivem melhor em locais de lucro máximo, o que muitas vezes leva a uma concentração de atividades em determinados lugares. Assim, eles irão se esforçar para descobrir caminhos para mercados que absorvem o excedente de capital e locais que possibilitem esse lucro máximo. Quando esses locais deixam de fornecer o lucro máximo, serão descartados; formando crises geograficamente localizadas em função de falência de fábricas locais e desemprego.

A partir disso, Harvey inaugura nova categoria denominando-a acumulação por espoliação. De acordo com ele, os mecanismos tradicionais de acumulação primitiva (expropriação das terras dos camponeses, privatização de terra, dívida pública, sistema de crédito, mercadificação da força de trabalho) continuam a existir. Porém, novos mecanismos de espoliação foram criados como privatização de bens públicos estatais, diminuição de regulações protetivas do trabalho, mercadificação da natureza. Esses processos são de interesse de investidores capitalistas, mas não são levados a cabo tão somente por eles. A participação estatal para engendrar esses processos é crucial.

Como esclarece Ribeiro Júnior (2013, p.7):

Em Marx, vimos como a terra transforma-se também em capital fictício o que resolve a contradição entre a teoria do valor e a existência da renda fundiária; Harvey (2010, p.97), por sua vez, atrela o capital fictício, "ativos em títulos ou notas promissórias desprovidos de suporte material, mas que podem ser usados como dinheiro", com o capital produtivo. Assim, se os gastos em ambientes construídos (portos, 
aeroportos, ferrovias, hidrelétricas, fábricas, etc.) ou melhorias sociais (habitações, etc.) se revelarem produtivos, os valores fictícios serão resgatados. Nesse sentido, a acumulação por espoliação libera ativos, como força de trabalho e matérias primas, a um baixo custo com vistas a resolver o problema da sobreacumulação e assim dar um destino lucrativo ao capital empregado/despendido.

A partir dessa base teórica é possível delinear alguns pontos importantes. Em primeiro, a terra urbana pode ser mercantilizada e pode ser compreendida na lógica do capital fictício. Dessa forma, vender e comprar a terra pelo valor que ela poderá ter no futuro passa a ser uma importante base para os processos de especulação imobiliária. Para tanto, esta terra precisa ter condições mínimas de adentrar nessa lógica, ou seja, é necessário haver um proprietário que disponibilize este espaço no mercado. Em segundo, é preciso haver meios de se valorizar aquele espaço como iluminação pública, esgoto, obras públicas, etc. em seu entorno.

Tendo em vista esta observação, terras e espaços urbanos que ainda não estavam inseridos nessa lógica podem passar a ser. Imagine agora terras que estavam fora de um mercado formal, em que pessoas a utilizam para sua moradia por vezes sem dispor de título de propriedade dessas terras. É o caso de algumas favelas, comunidades e ocupações. São espaços que imperam o valor de uso, o seu uso como moradia e que por vezes não dispõem de serviços públicos legalizados. Estes perfazem "um fora capitalista" no sentido de que aqueles espaços ainda não estão inseridos em um mercado formal de determinação de preço da terra e especulação imobiliária ${ }^{1}$. Além disso, os moradores desses territórios, no aspecto da moradia, também perfazem "um fora capitalista" por não estarem inseridos na lógica de produção capitalista da moradia, ou seja, não compram/vendem suas casas do mercado formal.

Este é um aspecto importante quando se inicia a análise das remoções no período preparatório dos megaeventos na cidade do Rio de Janeiro, tema do próximo tópico. Ademais, aliado a isso, tem-se os impactos da crise econômica mundial, comentada acima, e de crise política e fiscal na cidade do Rio de Janeiro em específico.

Em Nota Técnica no 37 da Diretoria de Estudos e Políticas Setoriais de Inovação e Infraestrutura do IPEA realizado por Glauter Rocha no ano de 2017, faz-se correlações importantes entre tais crises e os jogos olímpicos de $2016^{2}$. O pesquisador analisa a cidade do Rio de Janeiro em comparação com as capitais São Paulo, Salvador e Vitória nos períodos de 2012 a 2017 observando taxas de desocupação (que analisa tanto o emprego formal quanto outras formas de atividades remuneradas) e rendimento médio dos trabalhadores. Como apontado na pesquisa, a estratégia do Rio naquele período foi focar no desenvolvimento urbano através de melhorias na infraestrutura urbana com obras de mobilidade, drenagem, pavimentação, etc. e projetos de renovação e revitalização urbanas.

\footnotetext{
${ }^{1}$ Este é um ponto importante, pois é possível que estes espaços sejam comercializados e capitalizados de maneira informal pelos próprios moradores do local, mesmo que não se tenha titularidade da terra.

2 O estudo se chama "A economia dos Jogos Rio 2016: bastidores e primeiros impactos" e está disponível em: <

http://repositorio.ipea.gov.br/bitstream/11058/8049/1/NT_A\%20Economia_2017.pdf>. Acesso em 28 ago. 2019.
} 
Conforme resultados da pesquisa, nos anos de aceleração das obras, as taxas de desocupação na cidade carioca caíram e subiram um pouco nas fases de finalização das obras. Porém ainda assim, o desempenho do Rio foi superior quando comparado com aquelas capitais. Isso teria ocorrido em razão das megaoperações para realizar as obras preparatórias para os jogos e em razão dos investimentos nos setores de turismo e alimentação. Chegou-se a resultados similares no que diz respeito ao rendimento médio do carioca que aumentou em termos reais em 2012 e em 2016 e teve leve queda logo após o evento. Porém, ainda assim, o desempenho fora melhor do que em outras capitais. Apesar da redução das explorações de petróleo e gás em 2014, setor importante para a economia carioca, com a consequente demissão de muitos funcionários, os resultados foram positivos para a cidade naquele período. Conforme o pesquisador:

\begin{abstract}
Colateralmente, comportamento semelhante teve a trajetória do número de pessoas ocupadas na construção civil no Rio de Janeiro, a partir de 2014 (Gráfico 4), possivelmente sentindo os efeitos da queda dos investimentos do setor de petróleo e gás. A ocupação no setor, que se encontrava em ascensão até o final de 2013, sofreu forte choque em 2014, voltando a se recuperar em 2015. A aceleração das obras de preparação dos Jogos nesse período contribuiu para amenizar a queda de 2014 e, também, para a recuperação de 2015, auge do ritmo das obras de preparação do evento (IPEA, 2017, p. 12).
\end{abstract}

Porém, setores mais diretamente influenciados para a realização dos jogos, como aqueles de alimentação e alojamento, contribuiu para a diminuição da taxa de desocupação naquele período. Logo, a pesquisa conclui que há forte sinalização de que a preparação e realização dos jogos olímpicos favoreceram o dinamismo econômico na cidade em 2012-2016 retardando os efeitos da crise econômica.

Estes resultados nos é interessante por evidenciar a importância das obras e renovações urbanas quando em momentos de crise econômica ${ }^{3}$. Dessa forma, a transformação do território não era mais apenas uma demanda das comissões dos jogos, mas uma forma de sustentar a economia local em momentos de forte crise mundial.

Durante o período de preparação e realização dos megaeventos esportivos na cidade, a municipalidade engendrou remoções forçadas de pessoas em determinados espaços com a justificativa de realizar as obras públicas, em especial de mobilidade, e projetos de renovações necessárias. O que veremos a seguir é como as remoções se articulam com tudo isso.

As remoções forçadas: vislumbrando como espaço, capital e raça se articularam

Em razão dos megaeventos esportivos na cidade do Rio de Janeiro entre os anos de 2014 e 2016, fortaleceu-se a postura do poder público em remover pessoas que ocupavam determinados territórios na cidade, seja em favelas e/ou ocupações já consolidadas ou não. A justificativa das remoções eram as obras

\footnotetext{
${ }^{3}$ Harvey aponta isso no livro $O$ enigma do capital e as crises do capitalismo, exposto na bibliografia.
} 
preparatórias para tais eventos. À época, pesquisadores de universidades, militantes, moradores e associações se movimentaram seja na produção de relatórios sobre as atuações estatais seja na criação de movimentos de resistência aos processos.

Como expõe Müller (2016), a relatoria do Direito Humano à Cidade da Plataforma Direitos Humanos Econômicos, Sociais, Culturais e Ambientais (DHESCA) apurou em missão no ano de 2011 (Missão Megaeventos Esportivos na cidade do Rio de Janeiro e Violações aos Direitos Humanos) violações de direitos humanos quando das remoções. A missão expôs e denunciou o método utilizado pela Prefeitura Municipal para realizar as remoções. Conforme explica o autor,

\begin{abstract}
a missão denunciou também o método utilizado pelo município da cidade do Rio de Janeiro quando se deparava com uma comunidade à frente de um projeto de alargamento de avenida, teleférico ou uma obra de embelezamento da cidade. Ou então, quando apontava para uma comunidade sob qualquer justificativa jurídica viável para garantir sua remoção. As propostas que chegavam até as famílias por meio do Município sempre tinham como antecedência um mandado judicial de imissão na posse da área desapropriada pelo poder público contra as famílias. A partir daí se iniciavam as negociações que nada mais garantiam do que a indenização das benfeitorias da moradia do indivíduo atingido ou então ser reassentado em um programa habitacional do Minha Casa Minha Vida, mediante pagamento, em local longe de onde residiam. Esse procedimento está bem claro na primeira edição do dossiê do Rio de Janeiro realizado pelo Comitê Popular da Copa e Olimpíadas do Rio, juntamente com a Plataforma DHESCA Brasil (MÜLLER, 2016, p. 79,80).
\end{abstract}

Comunidades como Estradinhas, Largo do Campinho, Comunidade da Vila Metrô Mangueira, as ruas Machado de Assis e do Livramento na região do Porto, o Morro da Providência, a Vila Autódromo, a Vila Harmonia, Vila Recreio e a Restinga sofreram processos de remoção forçada (MÜLLER, 2016). Tais remoções ocorreram a partir de 2009, em razão dos megaeventos. Ao ser removida, a população poderia receber indenização, ser inserida no programa Minha Casa, Minha Vida, ou ainda receber aluguel social temporariamente (MAGALHÃES, 2016). Dessa forma, aquele espaço que servia de moradia para aquela população passa para a titularidade estatal, para a construção de vias de transporte ou para a requalificação de alguma área. O espaço passa a ter um proprietário e pode ser capitalizado. Aquela população removida entra para a lógica de um mercado formal de moradias, seja por financiar sua casa através do programa Minha Casa, Minha Vida (programa do governo federal que auxilia e subsidia a aquisição da casa própria. 0 financiamento é feito pela instituição bancária Caixa Econômica Federal), seja por comprar ou alugar casa com a indenização ou aluguel social que passa a receber (obviamente, há nesses dois casos a possibilidade da família ocupar novo território e permanecer fora do mercado formal aqui mencionado).

Falbo e Meirelles (2016) ao resgatar falas de algumas pessoas afetadas pela remoção exemplificam este aspecto. $\mathrm{O}$ estudo fora feito na comunidade Metrô-Mangueira, comunidade que passara por processos de remoção em razão das revitalizações no entorno do estádio Maracanã. Conforme a fala retratada no artigo, a opção dada pela Subprefeitura à época era um apartamento em Conjunto Habitacional que estava sendo construído na Zona Oeste da cidade. Haveria o financiamento da moradia perante a Caixa Econômica com 
inicial pagamento realizado pela Prefeitura. Além disso, haveria o pagamento pelos moradores de contas de água, luz, IPTU e condomínio. Observa-se que no território anterior, comunidade ou ocupação, não havia estes gastos. A população que estava fora dessa dinâmica capitalista de moradia passa a fazer parte dela quando é removida.

Há aqui a expropriação de um meio de sobrevivência dessas pessoas, a terra; e inserção dessa terra e dessas pessoas na lógica capitalista de moradia. Evidenciar esse aspecto é importante para compreender a articulação de capital e expropriação. Aqui, há o que alguns autores denominam acumulação primitiva que opera continuamente no modo de produção capitalista, ou a acumulação por espoliação como trata Harvey ou, ainda, de forma mais genérica expropriação de bens e direitos de uma população.

A relação entre remoção e crise econômica também se faz perceptível neste momento. Ao investir em desenvolvimento urbano se amenizou os efeitos da crise econômica na cidade. Este desenvolvimento se deu com obras e projetos de revitalização que se valeram de remoções forçadas para serem realizados em um curto espaço de tempo.

Entretanto, essas correlações entre transformação do território através das remoções e capital não se bastam. Há uma variável importante neste quesito: a raça. As comunidades/favelas na cidade do Rio possui grande concentração de afrodescendentes, como mencionado na Introdução. Pires (2016) a partir do enquadramento teórico da Interseccionalidade, observa como a vulnerabilidade é maior à medida que se correlaciona opressões diferentes. Há grupos em que várias formas de discriminação se combinam, estabelecendo vulnerabilidades específicas. Pires (2016) analisa, portanto, as remoções observando as opressões de gênero e raça que recaem nas mulheres não brancas residentes em favelas. A autora observa que as políticas de remoção tradicionalmente identificam apenas a subordinação de classe, ou seja, atingem a população pobre. Afinal, remoções forçadas ocorrem em favelas e ocupações, e não em bairros onde residem classes médias e altas. Porém, não se considera fatores como gênero e raça como fatores que vulnerabilizam ainda mais a população removida, invisibilizando demandas e opressões específicas.

Essa vulnerabilidade da população não branca tem origem histórica na escravidão e colonialismo brasileiros. Por grande parte da história brasileira, essa população sequer era considerada cidadã, afinal eram escravos, mercadorias a ser comprada e vendida. Após a abolição, esta população passa a ser formalmente considerada cidadã, porém os acessos a direitos e serviços públicos não eram os mesmos da população branca. Nota-se que a formalização é vazia quando o conteúdo daquela nova relação social - a liberdade dos escravos - é o mesmo de quando havia a escravidão. Tem-se uma população livre para vender, barato, sua força de trabalho e comprar seus meios de sobrevivência. Esses meios serão dificultados para essa população. Como expões Pires (2016) em referência a James Holston, a cidadania brasileira envolveu legislações e privilégios legais para a aquisição de terra, impedindo ou dificultando tal aquisição por determinados grupos. 
Dessa forma, ao falar de segregação e discriminação no espaço urbano, não se pode restringir ao aspecto de classe e renda. De fato, atinge-se a população pobre, porém esta não constitui um sujeito indivisível e uniforme. Ali se tem pessoas não brancas que estão sofrendo duplamente a opressão ${ }^{4}$. São pessoas que, historicamente eram consideradas coisas e mercadorias a ser comercializadas; sendo reconhecidas formalmente cidadãs em período recente da história brasileira. Entretanto, esse reconhecimento formal não foi acompanhado dos meios e condições reais de cidadania: moradia, emprego e acessos a serviços de qualidade. Esses aspectos históricos possuem efeitos na atualidade como quando se nota a maioria da população residente em favelas e ocupações. Dessa forma, ao correlacionar a classe e raça, nota-se que a falta de cidadania substantiva desta camada populacional se evidencia como um problema estrutural social. Isto significa que não se trata de um desvio ou atuação anormal por parte do poder público, mas de uma postura normalizada em que remover à força pessoas de suas moradias é possível quando se trata de negros favelados.

As remoções, portanto, evidenciam uma postura estatal que engendra opressões de classe e raça no território carioca. As leituras acima que observam as expropriações engendradas pelo Estado e pelo modo de produção capitalista observam parte do fenômeno. Ao incluir a variável raça, nota-se que as expropriações, ou seja, a retirada de bens e direitos, se dão em com as opressões.

Porém, no outro lado da moeda, evidencia também exigências e demandas sociais da população atingida que, não reconhecida como cidadã pelo Estado, se forma cidadã independentemente do Estado ao se organizar para resistir às remoções.

Magalhães (2016) ao analisar as remoções entre os anos de 2009 e 2011 analisa as mobilizações coletivas daquele período em conjunto com a atuação do Núcleo de Terras e Habitação (NUTH) da Defensoria Pública do Estado. De acordo com este autor, a ação do NUTH foi crucial no sentido de auxiliar a constituir estratégias de ação coletiva encabeçadas por moradores em situação de remoção. $O$ autor denomina esta ação de "trama movimentalista" “(...) isto é, um emaranhado de linhas de ação que se entrecruzaram a partir da crítica a estes processos, constituindo, assim, variadas mobilizações coletivas, sendo o NUTH um dos elementos centrais nesta estruturação" (MAGALHÃES, 2016, p. 209). Como mencionado pelo autor, os moradores das favelas sob risco de remoção se articulavam com o Conselho Popular - um movimento social formado por moradores de diferentes favelas que estavam sob risco de remoção ou que foram removidas no passado. A proposta é se distanciar das formas tradicionais de representação, valendo-se da presentação, ou seja, seus integrantes presentam-se a si mesmos e cuidam de seus interesses sem qualquer intermediação, sem alguém que fale por ele ${ }^{5}$. Havia articulação, ainda, através da Igreja com a Pastoral de Favelas. Quando

\footnotetext{
${ }^{4}$ Não se esquece aqui das mulheres e população LGBTTQI que porventura residam nestes locais. Trata-se apenas de um recorte feito no estudo ora apresentado.

${ }^{5}$ Como consta na própria apresentação do Conselho no site : https://conselhopopular.wordpress.com/sobre/. Acesso em 28 ago. 2019.
} 
os moradores ouviam rumores sobre remoção ou percebiam que esta ocorreria, eles procuravam formas de entender o que se passava e como reagir a isso. À época, muitas das indicações e orientações convergiam para o encaminhamento ao NUTH.

A postura então adotada era "entrar na justiça" (MAGALHÃES, 2016, p. 213), embora houvesse o receio de que o judiciário seria favorável à atuação municipal de remoção. A Defensoria então, após tentativas de resolução extrajudicial, entrava com as ações cabíveis judicialmente. Entretanto, esta ação judicial não era de decisão única daquela instituição, mas era conversada e apresentada para os moradores em reuniões do Conselho. Após a concordância dos moradores, a ação judicial era encaminhada (MAGALHÃES, 2016). É interessante evidenciar aqui o Direito sendo usado como arena de disputa política, afinal era o meio que tanto a Defensoria quanto a Prefeitura atuavam, o primeiro para impedir ou obstaculizar as remoções, o segundo para efetivá-la legitimamente.

As estratégias variavam conforme a situação e a favela a ser removida, porém o interessante é observar a articulação conjunta entre moradores, conselhos populares e um órgão estatal (a Defensoria Pública) que se utilizava do Direito para lidar com a situação. Embora fosse a Defensoria a detentora do saber técnico e dos meios para engendrar a situação, eram os moradores que encabeçavam a resistência, exigindo direito à moradia e respeito aos seus direitos nos processos de remoção. Isso se evidencia quando Magalhães (2016) retrata uma ação de moradores no dia em que uma das Ações Civis Públicas da Defensoria seria entregue no Tribunal de Justiça. Moradores organizaram manifestação em frente ao prédio deste Tribunal, levando cartazes e sacos de entulhos oriundos das demolições empreendidas pela Prefeitura.

Além do próprio auxílio institucional e técnico da Defensoria, que mobilizava politicamente o Direito em prol dos moradores removidos, houve articulação entre pesquisadores e acadêmicos com os moradores, como se evidencia pelos comitês populares e produção de pesquisas e artigos sobre as remoções.

É interessante observar que os movimentos sociais aqui relacionados não se pautavam por uma demanda trabalhista, como tradicionalmente se observava quando se falava em movimento social. $\mathrm{Na}$ verdade, foram movimentos pautados em moradia exigindo direito à moradia e respeito aos direitos humanos inclusive nos processos de remoções. Muitos dos artigos e pesquisas sobre as remoções, inclusive todos aqueles aqui referenciados, tratam das legislações brasileiras e internacionais sobre moradia e direitos humanos. A demanda, então, por vezes passava pela exigência de cumprimento de tais direitos, com uma esperança normativa no Direito. Talvez esta seja uma das características de alguns movimentos sociais atuais: formar-se enquanto cidadão apesar do Estado posicionando-se como aquele que tem direito a ter direitos.

Embora as remoções, em sua grande parte, de fato ocorreram e pessoas foram de fato removidas; articulações existiram, inclusive aquelas que se valeram de órgão estatal para impor algum tipo de resistência. 
Pode-se observar inclusive a insurgência estratégica de moradores e movimentos neste aspecto. Foi o caso da comunidade Vila Harmonia a quem, através do NUTH, foi dada liminar em 2010 para interromper remoções em curso em razão da Transoeste. No local subsistiam dois terreiros de Candomblé, religião de matriz africana ${ }^{6}$. Apesar de tudo, a comunidade fora removida de fato. Como expõe Legroux e Mendes (2016), após a implementação do BRT no local (onde existiam as comunidades Vila Harmonia, Restinga e Vila Recreio 2), a Prefeitura utilizou apenas $10 \%$ dos terrenos originalmente ocupados por aquelas comunidades, evidenciando ser desarrazoada a remoção total das comunidades; “o que motivou uma representação ao Ministério Público do Estado do Rio de Janeiro e uma visita realizada pela Câmara dos Vereadores e as ONGs Justiça Global e Anistia Internacional" (LEGROUX; MENDES, 2016, p. 37).

\section{CONCLUSÕES}

O objetivo deste estudo fora analisar a remoção e a resistência no espaço urbano carioca. A análise se embasou em uma revisão de literatura sobre o tema. $\mathrm{O}$ esforço foi de observar a relação cidade-raça-capital.

Em um primeiro momento se compreendeu o capitalismo contemporâneo, sua relação com o espaço e correlações da atual crise financeira com o espaço urbano carioca. Em segundo, recortou-se o objeto de análise trazendo o foco para os processos de remoção e resistência nos preparatórios dos megaeventos de 2014 e 2016, período posterior à crise econômica de 2007/2008 e momento em que os efeitos dessa crise estavam em pleno vapor em todo o mundo. Posteriormente, apresentei alguns estudos sobre algumas comunidades removidas procurando sempre centralizar a discussão da raça. Por fim, expus alguns estudos sobre tais processos que foram feitos à época apresentando uma característica interessante: uma das formas de resistência da população atingida. Foi observado que a população se organizou em comitês populares, fóruns e associações em conjunto com pesquisadores e acadêmicos universitários; além da mobilização e uso político do Direito e de instituições estatais para combater a própria ação estatal de remoção.

Este estudo perfaz o primeiro caminho de uma análise mais ampla sobre a relação cidade-raça-capital no espaço urbano carioca e que perfaz a pesquisa de doutorado. Dessa forma, neste artigo apresento algumas observações parciais originadas da investigação que ora se realiza. Estas observações são elementos cruciais para se começar a tangenciar o objeto de estudo. Como fora exposto, limitar o estudo do espaço urbano à relação cidade-capital olvida a dupla opressão que pessoas não brancas podem sofrer na cidade. Dupla por se submeter às opressões de classe e raça. Este fato se evidencia quando se analisa as recentes remoções no período preparatório dos megaeventos esportivos na cidade carioca. As comunidades removidas eram favelas onde há uma significativa parcela de pessoas negras em sua população. O recorte da raça é essencial quando

\footnotetext{
${ }^{6}$ Conforme informação jornalística obtida em : < https://fazendomedia.org/moradores-da-vila-harmonia-conseguem-liminar-parainterromper-remocoes-por-causa-da-transoeste/>. Acesso em 28 ago. 2019.
} 
se analisa aquele espaço urbano. Aliado à relação cidade-capital, observa-se expropriações e opressões que esta parcela populacional sofreu naquele período.

Entretanto, ações de resistência foram engendradas por esta população que se faz cidadã apesar do Estado. Estas ações de resistência tiveram considerável apoio técnico da Defensoria Pública, demonstrando o viés judicial das resistências e uma esperança normativa no Direito para a proteção dos atingidos, os quais exigiam judicialmente o direito a ter direitos e que estes fossem respeitados. Apesar de tudo, as remoções foram levadas à cabo para que o desenvolvimento urbano que as justificaram, as obras de mobilidade e projetos de renovação por exemplo, fossem realizadas.

\section{REFERÊNCIAS}

ABREU, Maurício. Contribuição ao estudo do papel do Estado na evolução da estrutura urbana. Revista Brasileira de Geografia, Rio de Janeiro, v. 43, n. 4, p. 577-585, 1981.

ABREU, Maurício. Reconstruire une histoire oubliée: Origine et expansion initiale des favelas de Rio de Janeiro. Geneses, Paris, n. 16, p. 45-68, 1994.

ABREU, Maurício. Da habitação ao habitat: A questão da habitação popular no Rio de Janeiro e sua evolução. Revista Rio de Janeiro, Rio de Janeiro, n. 10, p. 161-177, 2004.

ABREU, Maurício. A evolução urbana do Rio de Janeiro. Rio de Janeiro: IPP, 2006.

ABREU, Maurício; VAZ, Lílian. F. Sobre as origens da favela. IV Encontro Nacional da ANPUR, 1991, Salvador. Novas e Velhas Legitimidades na Reestruturação do Território - Anais do IV Encontro Nacional da ANPUR. Salvador: ANPUR, 1991. p. 481-492.

BOTELHO, Adriano. $O$ urbano em fragmentos: A produção do espaço e da moradia pelas práticas do setor imobiliário. São Paulo: Annablume, 2007.

CAMPOS, Andrelino de O. Do quilombo à favela: a produção do espaço criminalizado no Rio de Janeiro. 3a edição. Rio de Janeiro: Bertrand Brasil, 2010.

CAMPOS, Andrelino de O. As questões étnico-raciais no contexto da segregação socioespacial na produção do espaço urbano brasileiro: Algumas considerações teóricometodológicas. VV.AA Questões urbanas e racismo. Renato Emerson dos Santos (Org.). Petrópolis, RJ: DP et Alii; Brasília, DF: ABPN, 2012. P. 68-103

CARCANHOLO, Marcelo Dias. Conteúdo e forma da crise atual do capitalismo: lógica, contradições e possibilidades. Crítica e Sociedade: revista de cultura política. v.1, n.3, Edição Especial - Dossiê: A crise atual do capitalismo, dez. 2011.

CARRIL, Lourdes. Quilombo, Favela e Periferia: a longa busca da cidadania. São Paulo: Annablume: Fapesp, 2006.

CARVALHO, Lia de Aquino. Contribuição ao estudo de habitações populares: Rio de Janeiro 1866-1906. 2 ed. Rio de Janeiro: Secretaria Municipal de Cultura, Dep. Geral de Doc. e Inf. Cultural, Divisão de Editoração, 1995.

FALBO, Ricardo Nery; MEIRELLES, Manuela. Cidade do Rio de Janeiro, Comunidade Metrô Mangueira e Defensoria Pública. A resistência à remoção de favelas no Rio de Janeiro: instituições do comum e resistências urbanas: a história do núcleo de terras e habitação e a luta contra a remoção de favelas no Rio de Janeiro (2007-2011). Organização Alexandre F. Mendes, Giuseppe Cocco. 1. ed. - Rio de Janeiro : Revan, 2016.

GARCIA, Antonia dos Santos. Desigualdades raciais e segregação urbana em antigas capitais: Salvador, Cidade d'Oxum e Rio de Janeiro. 2006. Tese (doutorado) - Universidade Federal do Rio de Janeiro, IPPUR.

GONÇALVES, Guilherme Leite. Acumulação primitiva, expropriação e violência jurídica: expandindo as fronteiras da sociologia crítica do direito. Rev. Direito e Práxis, Rio de Janeiro, Vol. 08, N. 2, 2017, p. 1028-1082.

GONÇALVES, Guilherme Leite. COSTA, Sérgio. From primitive accumulation to entangled accumulation: Decentring Marxist Theory of capitalist expansion. European Journal of Social Theory XX(X), 1-19, 2019.

HARVEY, David. A produção capitalista do espaço. São Paulo: Annablume, 2005.

HARVEY, David. O enigma do capital e as crises do capitalismo. São Paulo, SP: Boitempo, 2011.

HARVEY, David. Os limites do capital. São Paulo: Boitempo, 2013. 
LEFEBVRE, Henri. O pensamento marxista e a cidade. Editora Ulisseia, 1972.

LEFEBVRE, Henri. $O$ direito à cidade. 5. ed. São Paulo: Centauro, 2008

LEFEBVRE, Henri. A produção do espaço. Trad. Doralice Barros Pereira e Sérgio

Martins (do original: La production de l'espace. 4e éd. Paris: Éditions Anthropos (2000). Primeira versão: início - fev.2006

LEGROUX, Jean; MENDES, Alexandre. BRT Transoeste: conflitos urbanos e contradições espaciais na "cidade atrativa”. Revista Direito e Práxis, Rio de Janeiro, Vol. 07, N.4,2016,p. 13-42.

LUXEMBURGO, Rosa. A acumulação do capital: estudo sobre a interpretação econômica do Imperialismo. Rio de Janeiro: Zahar Editores, 1970.

MARX, Karl. O capital: crítica da economia política. São Paulo: Boitempo, 2013. v. 1: o processo de produção do capital.

MARX, Karl. O capital: crítica da economia política. Edição: Friedrich Engels. São Paulo: Boitempo, 2017. v. 3: O processo global da produção capitalista.

MAGALHÃES, Alexandre. A atuação do Núcleo de Terras e Habitação da Defensoria Pública do Rio de Janeiro na trama movimentalista contra as remoções de favelas. A resistência à remoção de favelas no Rio de Janeiro: instituições do comum e resistências urbanas: a história do núcleo de terras e habitação e a luta contra a remoção de favelas no Rio de Janeiro (2007-2011). Organização Alexandre F. Mendes, Giuseppe Cocco. - 1. ed. - Rio de Janeiro: Revan, 2016.

MENDES, Alexandre. O Núcleo de Terras e Habitação no enfrentamento de um novo ciclo de remoções no Rio de Janeiro: o ano de 2009. A resistência à remoção de favelas no Rio de Janeiro: instituições do comum e resistências urbanas: a história do núcleo de terras e habitação e a luta contra a remoção de favelas no Rio de Janeiro (2007-2011). Organização Alexandre F. Mendes, Giuseppe Cocco. - 1. ed. - Rio de Janeiro : Revan, 2016.

MÜLLER, Christiano. As Remoções na cidade do Rio de Janeiro a partir de uma visão crítica dos direitos humanos. A resistência à remoção de favelas no Rio de Janeiro: instituições do comum e resistências urbanas: a história do núcleo de terras e habitação e a luta contra a remoção de favelas no Rio de Janeiro (2007-2011). Organização Alexandre F. Mendes, Giuseppe Cocco. - 1. ed. - Rio de Janeiro: Revan, 2016

MORAES, Antonio Carlos Robert. Bases da formação territorial do Brasil. In: Geografares, n. 2, Vitória, jun. 2011. P. 105-113.

OLIVEIRA, Natália S. Gentrificação e moradia social: como a política urbana pode atuar. Rio de Janeiro: Gramma, 2017.

PIRES, Carolina. O Direito à Moradia e as Desigualdades de Gênero e Raça. A resistência à remoção de favelas no Rio de Janeiro: instituições do comum e resistências urbanas: a história do núcleo de terras e habitação e a luta contra a remoção de favelas no Rio de Janeiro (2007-2011). Organização Alexandre F. Mendes, Giuseppe Cocco. - 1. ed. - Rio de Janeiro : Revan, 2016.

RATTS, Alex. Os lugares da gente negra: temas geográficos no pensamento de Beatriz Nascimento e Lélia Gonzalez. In: VV.AA. Questões urbanas e racismo. Renato Emerson dos Santos (Org.). Petrópolis, RJ : DP et Alii ; Brasília, DF : ABPN, 2012. P.216-243.

VAROUFAKIS, Yanis. O minotauro global: a verdadeira origem da crise financeira e o futuro da economia global. São Paulo: Autonomia Literária, 2016.

RIBEIRO, Luiz César de Queiroz. Dos cortiços aos condomínios fechados: as formas de produção da moradia na cidade do Rio de Janeiro. Rio de Janeiro: Civilização Brasileira: IPPUR, UFRJ: Fase, 1997.

RIBEIRO JÚNIOR, José Arnaldo dos Santos. Acumulação primitiva, capital fictício e acumulação por espoliação: introdução a uma leitura geográfica da economia capitalista contemporânea. Rev. Tamoios, São Gonçalo (RJ), ano 10, n. 1, págs. 55-66, jan/jun. 2014.

ROCHA, Oswaldo Porto. A era das demolições: cidade do Rio de Janeiro 1870-1920. 2ed. Rio de Janeiro: Secretaria Municipal de Cultura, Dep. Geral de Doc. e Inf. Cultural, Divisão de Editoração, 1995.

IPEA. Retrato das desigualdades de gênero e raça / Instituto de Pesquisa Econômica Aplicada [et al.]. - 4a ed. - Brasília: Ipea, 2011.

IPEA. A economia dos Jogos Rio 2016: bastidores e primeiros impactos. Nota Técnica n. 37. DISET (Diretoria de Estudos e Políticas Setoriais de Inovação e Infraestrutura), julho/2017.

SANTOS, Emerson dos. Sobre espacialidades das relações raciais: raça, racialidade e racismo no espaço urbano. In: VV.AA. Questões urbanas e racismo. Renato Emerson dos Santos (Org.). Petrópolis, RJ: DP et Alii; Brasília, DF: ABPN, 2012. P. 36-67.

SANTOS, Milton. Por uma economia política da cidade: o caso de São Paulo. 2. Ed. 1 reimpr. - Editora da Universidade de São Paulo, 2012.

SANTOS, Milton. Metamorfoses do Espaço Habitado: Fundamentos Teóricos e Metodológicos da Geografia. 6. ed. 2. reimpr. São Paulo: Editora da Universidade de São Paulo, 2014.

SMITH, Neil. Toward a theory of gentrification: a back to the city movement by capital, not people. In: Journal of the American Planning Association, Estados Unidos; Reino Unido; Singapura; Austrália, v. 45, n. 4, p. 538-548, out. 1979. 